\title{
Identidad - confluencia - trascendencia. Elementos para una interpretación histórico-especulativa del argumento de san Anselmo
}

\author{
Hernán Guerrero-Troncoso ${ }^{1}$
}

Resumen. Este trabajo pretende mostrar -mediante una interpretación del contexto dado por algunos capítulos clave del Monologion- que la función del argumento de san Anselmo consiste principalmente en determinar los términos a partir de los cuales es posible concebir un ser supremo, sobre la base de la identidad absoluta entre la esencia divina y todo lo que se muestra como propio de ella. Dicha identidad implicaría una confluencia no solamente de las propiedades en la esencia divina, sino sobre todo del ser en el pensar y viceversa. La trascendencia de una actividad en la otra, entendida como una remisión recíproca, permitiría mostrar el contexto especulativo en el cual se concibe la identidad absoluta de las propiedades en el ser supremo, así como también los criterios según los cuales aquello que se reconoce como perfecto en las criaturas puede ser considerado como propio de Dios.

Palabras clave: Anselmo de Canterbury, Argumento Ontológico, Interpretación, Ontología, Pensamiento Medieval, Primacía del Ser, Trascendentales.

\section{[en] Identity - Confluence - Transcendence.}

Key Aspects for a Historic-Speculative Interpretation of St. Anselm's Argument

\begin{abstract}
This article intends to demonstrate - by means of an interpretation of the context given by some key chapters of the Monologion - that the function of St. Anselm's argument consists mainly in determining the terms from which it is possible to conceive a supreme being, on the basis of the absolute identity between the divine essence and everything that presents itself as proper to it. This identity should imply a confluence, not only of the properties into the divine essence, but first of all of being into thinking and viceversa. The transcendence of one activity into the other, understood as a reciprocal reference, allows to show the speculative context in which the absolute identity of the properties in the divine being are conceived, as well as the criteria according to which that, which is recognized as a perfection in the creatures, can be considered proper to God as well.
\end{abstract}

Keywords: Anselm of Canterbury, Interpretation, Medieval Thought, Ontological Argument, Ontology, Primacy of Being, Transcendentals.

$1 \quad$ El presente artículo es parte del proyecto Fondecyt de Iniciación $N^{\circ}$ 11170810, titulado "Primacía del ser o primacía del ente. Un estudio comparado entre Enrique de Gante y Duns Scoto”. Agradezco a los evaluadores del artículo por las valiosas sugerencias para mejorar el texto, así como también a mis colegas Rodrigo Núñez Poblete y Javier Agüero Águila por su generosidad al leer distintas versiones del manuscrito y por sus agudas observacionesque enriquecieron el trabajo.

Universidad Católica del Maule, Talca, Chile

heguerrero@ucm.cl

Orcid ID: https://orcid.org/0000-0002-4236-449X 
Sumario. 1. Introducción. 2. El Monologion como presupuesto del Proslogion. La necesidad de una comprensión racional del Dios en el que se cree y de una determinación de los términos según los cuales la razón es capaz de concebirlo y manifestarlo. 2.1. La demostración de la existencia de Dios, concebido como el ser supremo, a partir de las criaturas (summum omnium quae sunt). 2.2. La "regula Anselmi" y los términos según los cuales la razón es capaz de concebir la esencia divina a partir de las perfecciones comunes a ambos. 2.3. La doctrina aviceniana de las primeras nociones del intelecto como punto de comparación para interpretar la regla anselmiana. 3. A modo de conclusión. Identidad, confluencia y trascendencia entendidas como presupuestos especulativos claves para interpretar el argumento del Proslogion y como antecedentes de una metafísica entendida como scientia transcendens.

Cómo citar: Guerrero-Troncoso, H. (2019). Identidad - confluencia - trascendencia. Elementos para una interpretación histórico-especulativa del argumento de san Anselmo, en Revista Anales del Seminario de Historia de la Filosofía 36 (3), 617-640.

\section{Introducción}

Si hay algo que de manera indiscutible se puede afirmar del argumento de san Anselmo, es que con el pasar de los siglos no ha cesado el interés por su estudio, a pesar de que haya sido objeto de críticas y de intentos de refutación ya desde la época de su formulación. En efecto, a lo largo de la historia es posible apreciar que escuelas o movimientos tan disímiles como la Escolástica, el Idealismo Alemán o la Filosofía Analítica, se han ocupado una y otra vez de interpretar y de reafirmar o refutar su validez ${ }^{2}$. Incluso uno de sus más célebres críticos -al menos en su formulación cartesiana $^{3}$-, Immanuel Kant, reconoció inicialmente, en su época precrítica, la validez de un argumento que afirma la existencia de Dios en cuanto ser necesario, en la medida en que es fundamento de la existencia de los seres que en sí son meramente posibles, e incluso hasta en su madurez expresó admiración por el argumento que denomina físico-teológico, a pesar de que no lo considerara concluyente ${ }^{4}$. Más recientemente, el interés en el argumento fue nuevamente suscitado a mediados del siglo pasado,

2 Para una panorámica de las diversas interpretaciones, cf. D. HASKIN, "The Ontological Argument and Theological Education”, en New Blackfriars 54/635 (1973) 148-156; C. GRANT, “Anselm's Argument Today”, en Journal of the American Academy of Religion 57/4 (1989) 791-806; N. VARISCO, "La 'ratio Anselmi' nell'interpretazione di alcuni pensatori medievali”, en Rivista di Filosofia Neo-Scolastica 90/1-2 (1998) 5-27.

3 Cf. J. McEvoy, "La preuve anselmienne de l'existence de Dieu est-elle un argument «ontologique»? À propos de trois interprétations récentes", en Revue Philosophique de Louvain 92/2-3 (1994) 167-183, donde el autor discute los artículos de R. Sokolowski, G. E. M. Anscombe y J.-L. Marion.

$4 \quad$ I. Kant, Der einzig mögliche Beweisgrund zu einer Demonstration des Daseins Gottes (ed. L. Kreimendahl - M. Oberhausen, Meiner, Hamburg 2011) 138-139. Tal como señalan los editores (ibíd. 255), la formulación con la que Kant concluye su escrito se puede interpretar tomando como punto de referencia las palabras de san Anselmo en el Proslogion. En lo que respecta a su admiración por el argumento físico-teológico, cf. Der einzig mögliche, 135: "Dieser kosmologische [bzw. physikotheologische] Beweis ist, wie mich dünkt, so alt wie die menschliche Vernunft. Er ist so natürlich, so einnehmend und erweitert sein Nachdenken auch so sehr mit dem Fortgang unserer Einsichten, daß er so lange dauern muß, als es irgendein vernünftiges Geschöpf geben wird, welches an der edlen Betrachtung teilzunehmen wünscht, Gott aus seinen Werken zu erkennen" (cf. la nota a este pasaje, ibíd. 249-250); Kritik der reinen Vernunft A 623-625/B 651-653 (ed. J. Timmermann, Meiner, Hamburg 1998) 693-694; Kritik der Urteilskraft, Allgemeine Anmerkung zur Teleologie (ed. H. F. Klemme, Meiner, Hamburg 2009) 417-418; G. B. SALA, Kant und die Frage nach Gott. Gottesbeweise und Gottesbeweiskritik in den Schriften Kants (De Gruyter, Berlin - New York 1990) 426-450. Sobre el paso del pensamiento precrítico al crítico en Kant en lo que respecta a las demostraciones de la existencia de Dios, cf. J. ScHMUCKER, Kants vorkritische Kritik der Gottesbeweise: ein Schlüssel zur Interpretation des theologischen Hauptstücks 
con la propuesta de N. Malcolm, según la cual en el capítulo 3 del Proslogion se encontraría un segundo argumento, que afirmaría que aquello que se debe considerar como una perfección no sería simplemente la existencia, como tradicionalmente se ha entendido, sino la existencia necesaria ${ }^{5}$.

Esta última propuesta, que ha sido discutida, defendida y cuestionada por un gran parte de los estudiosos contemporáneos, vuelve a poner en evidencia la complejidad del argumento de san Anselmo y la necesidad de un análisis que determine el espíritu que lo anima, espíritu que haría posible interpretar con mayor precisión el alcance de sus términos más allá de su simple formulación lógica ${ }^{6}$. Paradojalmente, esa complejidad queda en buena medida velada por la manera simple con que el arzobispo de Canterbury lleva a cabo su formulación, pero se puede apreciar claramente cada vez que se lleva adelante la tarea de interpretar su sentido y alcance tomando como punto de referencia la tradición filosófica precedente. Esta última, en efecto, puede ampliar los horizontes de interpretación más allá de la mera discusión lógica o sobre la fuerza demostrativa que pudiera tener, en la medida en que permite considerar al argumento como un hito en la historia de la metafísica, en una época en la cual pasa de ser concebida como una ciencia cuya tarea consiste principalmente en describir las propiedades del ser supremo y los términos en que todo lo que es depende de él, a una que se ocupa de las condiciones a partir de las cuales la realidad se constituye y se hace presente como real, es decir, a una metafísica que se plantea como una scientia transcendens ${ }^{7}$. En efecto, el argumento anselmiano no solo plantearía los términos a partir de los cuales sería necesario concebir a un ser supremo como actualmente existente -en tanto que incurriría en contradicción quien concibiera a Dios según los términos que propone el argumento y a la vez negara su existencia-, sino que al mismo tiempo reivindica el papel que juega el intelecto en la determinación de

der transzendentalen Dialektik der Kritik der reinen Vernunft (Akademie der Wissenschaften und der Literatur, Mainz 1983) 55-83; SALA, Kant und die Frage nach Gott, 200-218.

5 N. Malcolm, “Anselm's Ontological Arguments”, en The Philosophical Review 69/1 (1960) 41-62, aun cuando A. D. Smith señala (siguiendo en esto a A. Plantinga), que algo similar había sido planteado ya en 1941 por C. Hartshorne, cf. A. D. Sмiтh, Anselm's Other Arguments (Harvard University Press, Cambridge, MA - London, England 2014) 2-3.

6 Los estudios dedicados a reconstruir el argumento desde un punto de vista lógico han proliferado en las últimas décadas. Para una propuesta de los criterios para evaluar la validez de las formalizaciones, cf. G. EDER - E. RAMHARTER, "Formal reconstructions of St. Anselm's ontological argument", en Synthese 192/9 (2015) 2795-2825; R. S. Silvestre, "On the logical formalization of Anselm's ontological argument", en Revista Brasileira de Filosofia da Religião 2/2 (2015) 142-161; un resumen de las posiciones más importantes de las últimas décadas se encuentra en S. L. UCKERMAN, "The Reception of St. Anselm's Logic in the 20th and 21st Centuries", en G. E. M. GASPER - I. LogAn (eds.), Saint Anselm of Canterbury and His Legacy (Pontifical Institute of Mediaeval Studies, Toronto 2012) 405-426. Hay que destacar, asimismo, las monografías recientes de Sмiтн, Anselm's Other Arguments y R. CAMPBELL, Rethinking Anselm's Arguments. A Vindication of his Proof of the Existence of God (Brill, Leiden - Boston 2018).

7 Cf. L. Honnefelder, "Der zweite Anfang der Metaphysik. Voraussetzungen, Ansätze und Folgen der Wiederbegründung der Metaphysik im 13./14. Jahrhundert”, en J. P. Beckmann et al. (eds.), Philosophie im Mittelalter. Entwicklungslinien und Paradigmen (Meiner, Hamburg 1987) 165-186; ID., Scientia transcendens. Die formale Bestimmung der Seiendheit und Realität in der Metaphysik des Mittelalters und der Neuzeit (Duns Scotus Suárez - Wolff-Kant-Peirce) (Meiner, Hamburg 1990) 403-421; ID., "Metaphysik des Ersten oder Metaphysik des Ersterkannten? Überlegungen zum Konzept der Metaphysik bei Thomas von Aquin", en Philosophisches Jahrbuch 123/2 (2016) 443-457; T. KoutZarova, Das Transzendentale bei Ibn Sīnā. Zur Metaphysik als Wissenschaft erster Begriffs- und Urteilsprinzipien (Brill, Leiden - Boston 2009) 385-412; J. A. AERTSEN, Medieval Philosophy as Transcendental Thought. From Philip the Chancellor (ca. 1225) to Francisco Suárez (Brill, Leiden - Boston 2012) 75-100. 
la existencia de la esencia divina y, en general, de la comprensión de las propiedades de esta última.

Así, siguiendo la propuesta de un "segundo inicio" de la metafísica -el cual se habría consumado en propiedad en el pensamiento de Juan Duns Escoto, pero cuyas raíces se pueden apreciar ya en Avicena-, este trabajo pretende entregar algunos elementos que permitirían proponer una nueva perspectiva para interpretar el argumento anselmiano, en la cual el intelecto humano aparece como un elemento más a considerar para comprender la existencia y las propiedades de Dios. De acuerdo con esta nueva perspectiva -y en oposición a las críticas tradicionales al argumento, que se remontan a Gaunilo de Marmoutiers y cuyos exponentes más conocidos son santo Tomás de Aquino e Immanuel Kant-, se plantea como hipótesis que el argumento no tendría como finalidad demostrar la existencia de Dios a partir del hecho de que el intelecto lo conciba como un ser supremo, cuya existencia debe ser pensada como necesaria para no incurrir en contradicción, sino más bien que el argumento haría concebible cualquier afirmación relativa a Dios, incluyendo su existencia, ya que la fórmula anselmiana sería el modo más adecuado que tendría el intelecto humano para comprender la inmensidad de la esencia divina y su absoluta identidad con las propiedades que se conciben como propias de ella. En este sentido, el argumento anselmiano sería más bien la formulación del sentido en que es posible concebir al ser supremo, ya sea a partir de los términos en que se constituye en cuanto tal, como a partir del modo en que el intelecto humano es capaz de reconocer su existencia y sus determinaciones propias.

El presente trabajo, sin embargo, no aborda esa hipótesis directamente, sino más bien constituye una preparación para ella, a partir de dos aspectos que se consideran clave para interpretar el argumento del Proslogion, a saber, la demostración de la existencia de Dios - concebido en un primer momento como el bien supremo y luego como el ser supremo-y la formulación de una regla para determinar los modos en que es posible afirmar algo de la esencia divina. Dichos aspectos son expuestos por san Anselmo en los capítulos 1-4 y 15, respectivamente, del Monologion. Así, en primer lugar, se pretende mostrar que hay una relación de dependencia especulativa del Proslogion respecto del Monologion, en virtud de la cual este último texto entregaría el contexto en el que se debe interpretar el argumento anselmiano. Sobre este supuesto, se presentarán, en segundo lugar, los dos aspectos ya señalados, con especial énfasis en poner de manifiesto la comprensión de ser que subyace a la exposición de nuestro autor. En relación con este punto, la interpretación seguirá como hilo conductor las nociones de identidad, confluencia y trascendencia, para mostrar cómo en cierta medida el pensamiento anselmiano presagia el así llamado "segundo inicio" de la metafísica, dado que no solo pretendería describir aquello que es propio del ser supremo - una descripción que se articularía en torno a las nociones de identidad y confluencia-, sino también las condiciones a partir de las cuales es posible concebir dicho ser, que dirían relación con el carácter trascendental de lo que se puede afirmar que es propio de Dios. Para corroborar esta hipótesis, se tomará como punto de referencia el examen de Avicena de las primeras nociones del intelecto, pues dicho análisis permitiría distinguir mejor el sentido en que san Anselmo comprendería la noción de ser y su relación con los términos a partir de los cuales se conoce la realidad. Finalmente, se pondrán en evidencia los puntos de comparación que se pueden advertir entre la regla del Monologion y el argumento del Proslogion, a fin de que se aprecie el sentido y alcance de la hipótesis propuesta en relación con el carácter de dicho argumento. 


\section{El Monologion como presupuesto del Proslogion. La necesidad de una comprensión racional del Dios en el que se cree y de una determinación de los términos según los cuales la razón es capaz de concebirlo y manifestarlo}

Tal como el mismo san Anselmo lo señala en el prólogo del Proslogion, el Monologion ha de ser intepretado como una reflexión sobre el modo en que la razón humana es capaz de concebir la presencia efectiva del Dios en el que se cree, en la que se exponen los términos según los cuales dicha presencia puede ser aprehendida por la sola razón, sin que haya una remisión explícita a la Sagrada Escritura. En este sentido, en su segundo tratado, nuestro autor entrega una clave fundamental para interpretar ese "ejemplo de una meditación sobre la ratio fidei", a saber, que la meditación del primer tratado constituye solo uno de los modos posibles de concretar la tarea de una fe que va en busca de inteligibilidad, de una forma adecuada a la razón humana. Como dice nuestro autor, "no intento, Señor, penetrar en tu altura, porque de ninguna manera equiparo mi intelecto a ella, sino que deseo en alguna medida inteligir tu verdad, en la que cree y la que ama mi corazón”. Dicha búsqueda de inteligibilidad, es decir, esa pretensión de que el intelecto comprenda aquello en lo que cree y ama el corazón, vendría a ser el modo concreto en que la fe movería al hombre a pasar de una certeza inefable de la presencia efectiva de Dios - que sería la marca del creador impresa en la criatura-, a una comprensión adecuada a nuestro intelecto de aquello que es proprio de la esencia divina, a partir de la cual sería posible formular luego un discurso racional en torno a las propiedades de esa esencia. Por lo tanto, una vez que ha reconocido que se encuentra remitido a Dios, el hombre desea saber quién es ese Dios en el que cree, no al revés. En otras palabras, la íntima certeza de la presencia de Dios que se hallaría impresa en el corazón del hombre sería eso que lo impulsaría a buscar una comprensión racional del ser supremo. Tal comprensión por sí sola, en efecto, sería incapaz de hacer creer al ser humano de manera inequívoca en la presencia de Dios y, por ende, tampoco podría infundir en él el amor a Dios: "Y, de hecho, no busco inteligir para que pueda creer, sino que creo para que pueda inteligir. Pues creo también en esto, que "si no creyera, no inteligiría""?.

Sin embargo, ¿qué ocurre cuando al hombre le falta aquella certeza que le otorga la fe, a saber, la convicción originaria de que todo lo que existe, en último término, se remite a Dios y depende de él? ¿Solo alguien que posee dicha convicción se halla capacitado para preguntar por aquello que es propio del ser supremo? Sobre este punto, es necesario recordar que gran parte de aquello que el pensamiento cristiano considera como propio de la esencia divina ha sido igualmente concebido a lo largo

\footnotetext{
S. Anselmo de Canterbury, Proslogion, prol. (ed. F. S. Schmitt, Opera omnia, vol. 1, Nelson and Sons, Edinburgh 1946) 94; ibíd. c. 1 (ed. Schmitt, Opera 1) 100: "Fateor, domine, et gratias ago, quia creasti in me hanc imaginem tuam, ut tui memor te cogitem, te amem. Sed sic est abolita attritione vitiorum, sic est offuscata fumo peccatorum, ut non possit facere ad quod facta est, nisi tu renoves et reformes eam. Non tento, domine, penetrare altitudinem tuam, quia nullatenus comparo illi intellectum meum; sed desidero aliquatenus intelligere veritatem tuam, quam credit et amat cor meum. Neque enim quaero intelligere ut credam, sed credo ut intelligam. Nam et hoc credo: quia 'nisi credidero, non intelligam"'. Las traducciones en este trabajo son propias, pero se ha tenido a la vista la traducción de J. Alameda (Obras Completas de S. Anselmo, vol. 1, Biblioteca de Autores Cristianos, Madrid 2008, 188-348). Una comparación entre san Anselmo y san Agustín sobre el alcance de la "sola ratio" se encuentra en C. E. Viola, "Le Monologion face à la Philosophie Réflexive", en Recherches de théologie ancienne et médiévale 59 (1992) 97-110, en particular 102-105; G. B. Matthews, "Anselm, Augustine, and Platonism", en B. Davies - B. Leftow (eds.), The Cambridge Companion to Anselm (Cambridge University Press, Cambridge 2004) 61-83, en particular 65-71.
} 
de la historia por los pensadores no cristianos, no solo como adecuado para un ser supremo, sino también como digno de ser alcanzado en algún grado por los demás seres y como una perfección en sí, incluso si no se le considera expresamente como atributo de un ser divino, menos aun del Dios revelado. Por ende, la sola razón humana, que prescinde de la convicción de la existencia de Dios, podría perfectamente sostener lo que el cristianismo considera propio del ser supremo, en la medida en que este último pensamiento es capaz de plantear aquello en lo que cree en términos racionales.

En atención a este hecho, a partir de una reflexión que resulta del ejercicio de la pura razón y que no proviene de una experiencia de fe ni se remite a las autoridades sobre las que ésta se basa -la Sagrada Escritura o los Padres de la Iglesia, por ejemplo-, en los primeros capítulos del Monologion san Anselmo intenta reconducir a la comprensión cristiana aquello que los filósofos han podido concluir sobre un ser supremo, por medio del uso de su sola razón y según una estructura que recuerda el examen de Boecio en el libro III del De consolatione philosophiae ${ }^{9}$. Así, nuestro autor pretende mostrar que no hay una oposición entre aquello que la razón y la fe conciben cada una como cierto, sino que, incluso, habría una cierta confluencia en el concepto de la realidad más alta que poseen tanto el discurso racional como el que se funda en la fe. A fin de que sea más evidente esa confluencia que plantea el monje de Aosta, se expondrán, a continuación, dos aspectos de la meditación sobre la forma racional que puede adoptar la fe (el "exemplum meditandi de ratione fidei") que son relevantes para interpretar posteriormente el argumento del Proslogion. El primero de ellos se interpretará a partir de la identidad y la confluencia de las nociones de bien, magnitud y esencia, entendidas en grado sumo (Monologion, c. 1-4), y su determinación de los términos según los cuales sería lícito afirmar la pertenencia a la esencia divina de alguna perfección que tenga lugar en las criaturas (Monologion, c. 15).

\subsection{La demostración de la existencia de Dios, concebido como el ser supremo, a partir de las criaturas (summum omnium quae sunt)}

San Anselmo inicia el Monologion afirmando que, para demostrar la existencia necesaria de un ser supremo, que constituiría el fundamento de todo lo que consideramos real y existente, ha elegido el camino que estima más evidente para que cualquier persona -sea que crea en la Revelación o no-pueda reconocer la existencia de dicho ser supremo mediante el ejercicio de su sola razón. Ese reconocimiento se funda en la admisión de que dicho ser se debe concebir en último término como el bien supremo, el cual es suficiente para procurarse a sí mismo la felicidad y consumación, y que es, asimismo, causa de que todo lo que nos rodea y que es bueno y perfecto, lo sea ${ }^{10}$. El carácter evidente de ese camino se basa, a su vez, en el presupuesto de

$9 \quad$ A. M. T. S. Boecio, De consolatione philosophiae III (ed. C. Moreschini, Saur, Monachii - Lipsiae 2005) 5899; R. McMahon, Understanding the Medieval Meditative Ascent. Augustine, Anselm, Boethius \& Dante (The Catholic University of America Press, Washington DC 2006) 185-195; E. SweEney, Logic, Theology and Poetry in Boethius, Abelard and Alan of Lille. Words in the Absence of Things (Palgrave Macmillan, New York 2006) 43-45.

10 S. Anselmo, Monol. c. 1 (ed. Schmitt, Opera 1) 13: "Si quis unam naturam, summam omnium quae sunt, solam sibi in aeterna sua beatitudine sufficientem, omnibusque rebus aliis hoc ipsum quod aliquid sunt aut quod aliquomodo bene sunt, per omnipotentem bonitatem suam dantem et facientem, aliaque perplura quae de Deo sive de eius creatura necessarie credimus, aut non audiendo aut non credendo ignorat: puto quia ea ipsa ex magna parte, si vel mediocris ingenii est, potest ipse sibi saltem sola ratione persuadere". 
que toda acción humana se halla movida por el deseo de disfrutar de aquello que juzga bueno, sobre todo de aquello que se muestra como un bien suficiente para sí mismo, es decir, que se disfuta porque es ese bien en particular, y no en vista de otro bien superior. En efecto, nuestro autor sostiene que, si en lugar de que el hombre se concentrara simplemente en conocer aquello que considera bueno bajo determinadas circunstancias, en el objeto particular que desea o en la actividad cuya realización estima buena, y se dedicara más bien a determinar en qué consiste aquello a partir de lo cual proviene toda bondad que pudiera desear, en términos absolutos, ascendiendo de este modo a bienes mayores y más perfectos, terminaría por afirmar la existencia de aquel ser que consiste en el bien supremo ${ }^{11}$.

Ahora bien, para que la existencia de este bien supremo pueda ser reconocida de manera objetiva, o, mejor dicho, para que su afirmación no sea arbitraria, es necesario considerar dos elementos. El primero consiste en el carácter objetivo del deseo del hombre por alcanzar no solo aquello que considera bueno, sino sobre todo aquello que estima mejor, es decir, un bien mayor que los demás. Dicho deseo podría parecer a primera vista algo meramente subjetivo, ya que, como señala el monje de Aosta, dada la pluralidad de cosas y acciones buenas y de condiciones según las cuales algo puede constituirse como bueno, se hace difícil sostener que haya algo uno, en virtud de lo cual esa pluralidad de bienes se determine como bueno y, por consiguiente, es lícito preguntarse si los bienes se ordenan entre sí según principios diversos, o bien si es nuestra razón la que en último término determina la bondad de una cosa o de una acción, según los propios intereses y apetitos ${ }^{12}$. Esta última posibilidad, que Anselmo no considera en el Monologion, encuentra una respuesta en su tratado sobre el libre albedrío, en donde sostiene que la libertad consiste en querer el bien. En efecto, en lugar de definir el libre albedrío como la posibilidad de pecar o de no pecar - esto es, de hacer o no el bien-, nuestro autor lo comprenderá como "el poder dado a la naturaleza racional para observar la rectitud propia de la voluntad, en virtud de la rectitud misma"13 $\mathrm{y}$, más aun, afirmará que "no hay voluntad más libre que la voluntad recta, a la cual ninguna fuerza ajena le puede remover su rectitud"14. Por lo tanto, puesto que la voluntad es libre en la medida en que hace el bien, no se podría sostener un fundamento puramente subjetivo $-\mathrm{y}$, con ello, arbitrario- para desear el bien y para determinar aquello que se considera bueno, sino que dicho fundamento sería objetivo, a saber, consistiría en el bien que se quiere por sí mismo, el cual debería existir con independencia del deseo por alcanzarlo.

El segundo elemento consiste en la unidad del fundamento objetivo de la bondad de todo cuanto se considera bueno, a saber, que la multiplicidad de cosas y acciones buenas a las que alude san Anselmo debe poseer un único fundamento, en virtud

11 S. Anselmo, Monol. c. 1 (ed. Schmitt, Opera 1) 13-14: "Etenim cum omnes frui solis iis appetant quae bona putant: in promptu est, ut aliquando mentis oculum convertat ad investigandum illud, unde sunt bona ea ipsa, quae non appetit nisi quia iudicat esse bona, ut deinde ratione ducente et illo prosequente ad ea quae irrationabiliter ignorat, rationabiliter proficiat".

12 Cf. S. Anselmo, Monol. c. 1 (ed. Schmitt, Opera 1) 14: "Facile est igitur ut aliquis sic secum tacitus dicat: Cum tam innumerabilia bona sint, quorum tam multam diversitatem et sensibus corporeis experimur et ratione mentis discernimus: estne credendum esse unum aliquid, per quod unum sint bona quaecumque bona sunt, an sunt bona alia per aliud?".

13 S. Anselmo, De libertate arbitrii c. 3 (ed. Schmitt, Opera 1) 212: "Ergo quoniam omnis libertas est potestas, illa libertas arbitrii est potestas servandi rectitudinem voluntatis propter ipsam rectitudinem".

14 S. Anselmo, De lib. arb. c. 9 (ed. Schmitt, Opera 1) 221: "Nihil liberius recta voluntate, cui nulla vis aliena potest auferre suam rectitudinem". 
del cual ellas sean buenas. Aquí se puede apreciar, en primer lugar, que la bondad consiste en algo distinto de la determinación de cada cosa o acción que se constituye como buena y, por lo tanto, que la bondad no depende de las determinaciones de la cosa que se concibe como buena, sino que las trasciende. Dicho de otro modo, si una acción o una cosa es buena, lo es en virtud de la bondad presente en ella, y no porque se trate de esa acción o cosa en particular. Por consiguiente, la bondad ha de ser concebida como algo común a todas las cosas y acciones, anterior a ellas, que posee el mismo sentido para todas y que tiene lugar en ellas en mayor o menor grado ${ }^{15}$. Así, esta caracterización de la bondad dejaría en evidencia que el arzobispo de Canterbury no la consideraría como una mera cualidad de las cosas, como un accidente más de la sustancia, sino que la concebiría más bien en un sentido trascendental, pues superaría y precedería a toda determinación de las cosas, las abarcaría en su totalidad $\mathrm{y}$, finalmente, las remitiría a aquello que es bueno en sí, al bien supremo, el cual se encuentra más allá del ámbito de las criaturas.

La presencia de dicho bien trascendental tendría lugar en las criaturas de dos maneras, a saber, en cuanto útil y en cuanto honesto, en atención a si constituye causa del bien para otro, o si consiste en algo bueno en sí mismo. Así, san Anselmo ilustra el primer sentido con el ejemplo de un caballo, del cual se dice que es bueno porque es fuerte y veloz. Aun cuando se podría pensar que dichas cualidades hacen bueno al caballo, en realidad ninguna de ellas por sí mismas lo hacen bueno, ya que un ladrón que poseyera las mismas características sería un ladrón más dañino que uno que careciera de ellas. Por lo tanto, si el caballo se considera bueno por ser fuerte y veloz, su bondad no radica en el hecho de que esas cualidades constituyan un bien para él mismo, sino porque lo son para otro - para su dueño, por ejemplo- ${ }^{16}$. Lo honesto, por otro lado, consiste en aquello que permite que algo se conciba como bueno en cuanto tal, ya sea porque determina a una cosa o acción como buena en sí misma, o bien porque hace posible alcanzar la bondad ${ }^{17}$. En este caso, no se trataría de un bien que determinaría a otro en cuanto bueno - a una acción o a una cualidad, que en sí no son ni buenas ni malas-, sino de algo que concretaría en sí mismo un aspecto del bien, de tal manera que su opuesto sería inmediatamente un mal.

Ahora bien, si se debe admitir que lo útil y lo honesto constituyen un bien existente, que su presencia en otro hace bueno a este último, y que nada es bueno por sí mismo, sino a causa de aquello en virtud de lo cual todo es bueno -es decir, que todo cuanto se muestra como bueno, lo hace según un cierto grado en que el bien se hace presente en él-, resulta que esto último debería ser concebido con mayor razón

15 S. Anselmo, Monol. c. 1, (ed. Schmitt, Opera 1) 14: "Certissimum quidem et omnibus est volentibus advertere perspicuum quia, quaecumque dicuntur aliquid ita, ut ad invicem magis vel minus aut aequaliter dicantur: per aliquid dicuntur, quod non aliud et aliud sed idem intelligitur in diversis, sive in illis aequaliter sive inaequaliter consideretur. Nam quaecumque iusta dicuntur ad invicem sive pariter sive magis vel minus, non possunt intelligi iusta nisi per iustitiam, quae non est aliud et aliud in diversis. Ergo cum certum sit quod omnia bona, si ad invicem conferantur, aut aequaliter aut inaequaliter sint bona, necesse est, ut omnia sint per aliquid bona, quod intelligitur idem in diversis bonis, licet aliquando videantur bona dici alia per aliud".

16 S. Anselmo, Monol. c. 1, (ed. Schmitt, Opera 1) 14: "Per aliud enim videtur dici bonus equus quia fortis est, et per aliud bonus equus quia velox est. Cum enim dici videatur bonus per fortitudinem et bonus per velocitatem, non tamen idem videtur esse fortitudo et velocitas. Verum si equus, quia est fortis aut velox, idcirco bonus est: quomodo fortis et velox latro malus est? Potius igitur, quemadmodum fortis et velox latro ideo malus est quia noxius est, ita fortis et velox equus idcirco bonus est quia utilis est".

17 S. Anselmo, Monol. c. 1 (ed. Schmitt, Opera 1) 14: "Et quidem nihil solet putari bonum nisi aut propter aliquam utilitatem, ut bona dicitur salus et quae saluti prosunt, aut propter quamlibet honestatem, sicut pulchritudo aestimatur bona et quae pulchritudinem iuvant". 
como existente y como un bien de gran magnitud (magnum bonum). A diferencia de los demás seres, este bien no requeriría de otro para ser bueno, sino que se bastaría a sí mismo para determinarse como tal y, por consiguiente, ningún otro ser podría ser igual o mayor a él en magnitud, sino que este bien sería mayor que cualquier otro, único y supremo ${ }^{18}$. Como resultado de esta reflexión, que muestra una confluencia intrínseca entre lo bueno por sí mismo y la magnitud suprema -ya que, precisamente porque se basta a sí mismo y es causa de todo otro bien, ese bien constituye el grado supremo de la bondad-, san Anselmo concluye que dicha confluencia entre bien y magnitud, ambos en grado supremo, se debe concebir como una identidad:

Esto, en efecto, es supremo, [a saber,] aquello que es de tal manera sobreeminente a los demás, que no puede tener ni un semejante ni algo más excelente. Pero aquello que es bueno en grado supremo es asimismo grande en grado supremo. Hay, por lo tanto, algo uno, que es bueno en grado supremo y grande en grado supremo, esto es, lo más supremo de todo cuanto es ${ }^{19}$.

En este pasaje es posible apreciar que la confluencia entre bien y magnitud había estado presente desde el inicio de la exposición, ya que cualquier grado en que el bien se manifieste en las cosas y acciones que son buenas constituye una cierta magnitud de éste. Sin embargo, solo cuando se trata de un bien supremo, suficiente para sí mismo y para todo lo demás, se puede afirmar una identidad entre magnitud y bien, en virtud, precisamente, del carácter supremo de ambos. Ahora bien, tal como explica san Anselmo, la magnitud no se debe concebir en sentido simplemente cuantitativo, como si se tratara de un espacio -o, mejor dicho, de una extensión-, sino más bien en términos cualitativos. En este sentido, la magnitud suprema consistiría en algo que, "cuanto más grande, es tanto mejor o más digno, como la sabiduría" ${ }^{20}$. En otras palabras, un grado mayor de bien implica una mayor perfección para aquello en lo que tiene lugar el bien, y no solamente una mayor capacidad de ponerse de manifiesto en otros o de acoger a otros en sí. Por lo tanto, el carácter supremo no sería extensivo, sino intensivo y, por consiguiente, el ser supremo sería lo mismo que el bien supremo, ya que aquel consistiría en el grado máximo de perfección. De este modo, el arzobispo de Canterbury reafirmaría la identidad entre el bien supremo y la magnitud suprema en virtud del carácter supremo común a ambos, ya que ese grado supremo en el que confluyen no haría más que constatar una remisión recíproca intrínseca a ellos y, con eso, reafirmaría la necesidad de afirmar la existencia de aquello que constituye el grado de perfección absoluta ${ }^{21}$.

18 S. Anselmo, Monol. c. 1 (ed. Schmitt, Opera 1) 14-15: "Sed quoniam iam perspecta ratio nullo potest dissolvi pacto, necesse est omne quoque utile vel honestum, si vere bona sunt, per idipsum esse bona, per quod necesse est esse cuncta bona, quidquid illud sit. Quis autem dubitet illud ipsum, per quod cuncta sunt bona, esse magnum bonum? Illud igitur est bonum per seipsum, quoniam omne bonum est per ipsum. Ergo consequitur, ut omnia alia bona sint per aliud quam quod ipsa sunt, et ipsum solum per seipsum. At nullum bonum, quod per aliud est, aequale aut maius est eo bono, quod per se est bonum. Illud itaque solum est summe bonum, quod solum est per se bonum".

19 S. Anselmo, Monol. c. 1 (ed. Schmitt, Opera 1) 14-15: "Id enim summum est, quod sic supereminet aliis, ut nec par habeat nec praestantius. Sed quod est summe bonum, est etiam summe magnum. Est igitur unum aliquid summe bonum et summe magnum, id est summum omnium quae sunt".

20 S. Anselmo, Monol. c. 2 (ed. Schmitt, Opera 1) 15: "Dico autem non magnum spatio, ut est corpus aliquod; sed quod quanto maius tanto melius est aut dignius, ut est sapientia".

21 S. Anselmo, Monol. c. 2 (ed. Schmitt, Opera 1) 15: "Et quoniam non potest esse summe magnum nisi id quod est summe bonum, necesse est aliquid esse maximum et optimum, id est summum omnium quae sunt". 
Por consiguiente, aquella remisión recíproca entre bien y magnitud, que se consuma en la identidad entre el bien supremo y la magnitud suprema, no se puede concebir simplemente como una relación, sino que debe constituir algo uno por sí mismo, que a su vez vendría a ser la causa por la cual todo lo que es algo pueda serlo ${ }^{22}$. En efecto, solo "algo" puede ser causa de otro "algo", ya que la pura nada no es capaz de dar lugar a "algo", dado que en sí no consiste sino en nada, y de ella nada surge, como sostiene el adagio ${ }^{23}$. Por consiguiente, dado que todo cuanto es -0 , mejor dicho, todo "algo" - tiene lugar a partir de otro "algo", Anselmo considera necesario determinar -tal como lo hizo con el bien y la magnitud-si acaso todo surge de un solo principio o de muchos, ya sea porque cada uno de esa multitud es suficiente para sí mismo, o bien porque cada uno depende a su vez de los demás. Ahora, del examen que lleva a cabo nuestro autor resulta que, incluso si se afirma una multiplicidad de principios, sea como sea que se plantee su relación con la unidad-incluso si se negara o se omitiera dicha relación-, la multiplicidad necesariamente confluye en un solo principio, del cual depende todo lo demás. Dice san Anselmo:

Por lo tanto, todo cuanto es, no es sino por algo. Siendo así las cosas, o es uno o son muchos, aquello por lo cual es todo cuanto es. Pero si son muchos, estos están referidos a algo uno por lo cual son, o bien cada uno de esos muchos es por sí mismo, o bien ellos son los unos en relación con los otros. Ahora bien, si los muchos son por uno, ya no son todos por muchos, sino más bien por aquel uno ... $\mathrm{Si}$, por el contrario, cada uno de aquellos muchos es por sí mismo, de cualquier modo hay una cierta fuerza o naturaleza para que puedan existir por sí mismos, la cual poseen para que sean por sí mismos. Sin embargo, no hay duda de que son por esto uno, por lo cual tienen cómo poder ser por sí mismos ... En cambio, que los muchos sean los unos en relación con los otros no se puede aceptar por ninguna razón, dado que es una concepción irracional que alguna cosa sea por aquello a lo cual da el ser. Porque ni siquiera los mismos términos relativos son el uno en relación con el otro ... Y así, como la verdad excluye de cualquier modo que los muchos sean aquello por lo cual todo sería, es necesario que aquello uno sea, eso por lo cual es todo aquello que $\mathrm{es}^{24}$.

De esta manera, puesto que la totalidad de las cosas dependen de ese único primer principio para ser ese "algo" que cada una es, con mayor razón ese principio debe ser por sí mismo, es decir, suficiente para determinarse y existir por sí solo. Dicha dependencia opera como una confirmación externa de su supremacía y primacía,

22 S. Anselmo, Monol. c. 3 (ed. Schmitt, Opera 1) 15: "Denique non solum omnia bona per idem aliquid sunt bona, et omnia magna per idem aliquid sunt magna, sed quidquid est, per unum aliquid videtur esse".

23 Cf. Boecio, De consol. phil. V.1.9 (ed. Moreschini) 136-137: "Nam nihil ex nihilo exsistere vera sententia est, cui nemo umquam veterum refragatus est".

24 S. Anselmo, Monol. c. 3 (ed. Schmitt, Opera 1) 16: "Quidquid est igitur, non nisi per aliquid est. Quod cum ita sit, aut est unum aut sunt plura, per quae sunt cuncta quae sunt. Sed si sunt plura, aut ipsa referuntur ad unum aliquid per quod sunt, aut eadem plura singula sunt per se, aut ipsa per se invicem sunt. At si plura ipsa sunt per unum, iam non sunt omnia per plura, sed potius per illud unum ... Si vero ipsa plura singula sunt per se, utique est una aliqua vis vel natura existendi per se, quam habent, ut per se sint. Non est autem dubium quod per id ipsum unum sint, per quod habent, ut sint per se ... Ut vero plura per se invicem sint, nulla patitur ratio, quoniam irrationabilis cogitatio est, ut aliqua res sit per illud, cui dat esse. Nam nec ipsa relativa sic sunt per invicem ... Cum itaque veritas omnimodo excludat plura esse per quae cuncta sint, necesse est unum illud esse, per quod sunt cuncta quae sunt". 
puesto que todo cuanto es distinto de él, le es inferior y, por consiguiente, constituye lo único que es en grado máximo y supremo ${ }^{25}$.

Sin embargo, la distinción más relevante que observa san Anselmo es aquella que tiene lugar al interior del ser supremo, la cual consiste en la primacía de la esencia sobre las demás determinaciones de las que se ha ocupado hasta ahora, el bien y la magnitud. En efecto, si el carácter supremo aparecía como el fundamento de la identidad entre esas determinaciones -a saber, como aquello que permitía que el bien supremo y la magnitud suprema debieran ser concebidas como eso que es en grado sumo-, en este capítulo el monje de Aosta reconoce que el ser supremo tiene que ser algo, "sea que se le llame esencia, sustancia o naturaleza, es lo mejor, lo máximo y lo supremo de todo cuanto es"26. En este sentido, a pesar de que el ser supremo es intrínsecamente bueno y grande, en grado sumo, debe ser concebido antes que nada como una sustancia, es decir, como aquello que no se encuentra en un sujeto, sino que él mismo subyace a todo lo demás, lo cual a su vez tiene lugar en la medida en que se halla en él ${ }^{27}$. Por ende, el bien supremo y la magnitud suprema constituyen determinaciones propias del ser supremo mediante las cuales se despliega su sustancia.

En este punto, se advierte que el arzobispo de Canterbury ha llegado al meollo de su argumentación y que, una vez ahí, ha dado un giro en relación con el modo en que había procedido hasta ese momento. En efecto, el bien supremo y la magnitud suprema, que hasta ahora habían llevado adelante el examen, se muestran en último término como subordinados a la esencia suprema, a pesar de que entre ellos se da una identidad tal, que permite sostener que la magnitud y el bien supremos son lo mismo que el ser supremo, en virtud de la supremacía común a ellos. El camino seguido por san Anselmo para demostrar que es posible reconocer la existencia de un ser supremo de manera meramente racional, un camino hasta ahora ascendente, desde las criaturas al creador, se convierte en un camino descendente, mediante el cual nuestro autor muestra, por una parte, la dependencia de las criaturas con respecto de su creador y, por otra parte, la confluencia de las determinaciones propias del ser supremo de la esencia de este último. En este sentido, la identidad entre el bien supremo y la magnitud suprema no se debería solamente a la remisión

25 S. Anselmo, Monol. c. 3 (ed. Schmitt, Opera 1) 16: "Quoniam ergo cuncta quae sunt, sunt per ipsum unum, proculdubio et ipsum unum est per seipsum. Quaecumque igitur alia sunt, sunt per aliud, et ipsum solum per seipsum. At quidquid est per aliud, minus est quam illud per quod cuncta sunt alia, et quod solum est per se. Quare illud quod est per se, maxime omnium est. Est igitur unum aliquid, quod solum maxime et summe omnium est".

26 S. Anselmo, Monol. c. 3 (ed. Schmitt, Opera 1) 16: “Quod autem maxime omnium est, et per quod est quidquid est bonum vel magnum, et omnino quidquid aliquid est id necesse est esse summe bonum et summe magnum, et summum omnium quae sunt. Quare est aliquid, quod, sive essentia sive substantia sive natura dicatur, optimum et maximum est et summum omnium quae sunt".

27 Cf. Aristóteles, Categoriae c. 5, 3a 7-8 (translatio Boethii, editio composita [vulgata], ed. L. Minio-Paluello, Aristoteles Latinus, vol. 12, Desclee de Brouwer, Bruges - Paris 1961) 50: "Commune autem est omni substantiae in subiecto non esse"; AvicenA, Liber de Philosophia prima sive Scientia divina II c. 1 (ed. S. van Riet, Avicenna Latinus, vol. 3, Peeters - Brill, Louvain - Leiden 1977) 65: "Aliud [modus esse] est quod est, sed non est in aliquo hoc modo [scil. in subiecto], quoniam nullatenus est in subiecto, et hoc est substantia". Sobre la primacía de la sustancia sobre las demás categorías, cf. G. GALluzzo, The Medieval Reception of Book Zeta of Aristotle's Metaphysics. Aristotle's Ontology and the Middle Ages: The Tradition of Met., Book Zeta (Brill: Leiden - Boston 2013, vol. 1) 21-27; sobre la influencia de las Categorías de Aristóteles, cf. P. GILBERT, "«Id est summum omnium quae sunt» (S. Anselme, «Monologion», chap. I-IV)", en Revue Philosophique de Louvain 82/54 (1984) 199-223, en particular 208-210; C. ERISMANN, "Un autre aristotélisme? La problématique métaphysique durant le haut Moyen Âge latin. À propos d'Anselme, Monologion 27', en Quaestio 5 (2005) 145-162, en particular 154-162. 
recíproca entre sí, es decir, al hecho de que el bien trascienda en la magnitud y viceversa, sino, por el contrario, que el fundamento de su identidad radicaría más bien en la presencia de ambas determinaciones en el ser supremo, el cual constituye el grado máximo en sentido cualitativo (optimum), cuantitativo (maximum) y esencial (summum).

Precisamente del carácter supremo de la esencia, naturaleza o sustancia divina se ocupa san Anselmo en el capítulo 4, con lo cual concluye su meditación sobre su determinación y existencia ${ }^{28}$. Al igual que como ocurre con el bien y la magnitud, nuestro autor sostiene que en las sustancias se da un mayor o menor grado de dignidad o perfección. "De hecho", dice Anselmo, "quien dude que en su [propia] naturaleza, mejor que la madera sea el caballo y más excelente que el caballo sea el hombre, quizás no debería ser llamado hombre" ${ }^{29}$. Este presupuesto -que introduce en la sustancia una característica que la metafísica tradicional concibe como propia de la relación entre las sustancias segundas, género y especie, pero no de las sustancias primeras ${ }^{30}$ - sigue la misma relación de confluencia que se observa en el bien y la magnitud, solo que esta vez, en lugar de que la remisión recíproca tenga lugar entre las sustancias, se daría más bien entre las sustancias dependientes y el ser supremo, del cual dependen. Por lo tanto, los grados de perfección entre las sustancias constituirían una señal de mayor o menor cercanía del ser supremo, al tiempo que excluirían la posibilidad de una remisión al infinito en dichos grados. En efecto, de esa imposibilidad de una infinitud de grados de perfección, san Anselmo concluye la necesidad de que haya una naturaleza suprema, absolutamente primera, cuya perfección supere en un grado tan grande la de los demás seres, que sea imposible que se encuentre sometida a otra sustancia ${ }^{31}$.

A partir de esto queda en evidencia que el mero carácter supremo de la esencia divina y sus determinaciones, por sí solo, no es fundamento suficiente para postular la necesidad de su existencia. Dicho postulado solo es posible bajo la condición de una primacía absoluta de su esencia, esto es, que sea a la vez imposible e inconce-

28 Cf. Gilbert, “«Id est summum omnium...»”, 217-220.

29 S. Anselmo, Monol. c. 4 (ed. Schmitt, Opera 1) 17: "Qui enim dubitat quod in natura sua ligno melior sit equus, et equo praestantior homo, is profecto non est dicendus homo".

30 Cf. Aristóteles, Cat. c. 5, 2b 8-29 (ed. Minio-Paluello, AL 1²) 49-50: "Secundarum vero substantiarum maxime substantia est species quam genus; propinquior enim est primae substantiae ... Amplius principales substantiae, eo quod aliis omnibus subiectae sint et alia omnia de his praedicentur, aut in eis sunt, ideo maxime dicuntur substantiae ... Quare et ex his species genere magis substantia est ... Similiter autem et principalium substantiarum nihil magis alterum alterius substantia est; nihil enim magis aliqui homo substantia est quam aliqui bos"; ibíd. 3b 34-39 (ed. Minio-Paluello, AL 12) 52: "Videtur autem substantia non suscipere magis et minus; dico autem hoc non quia substantia non est a substantia magis et minus ... sed quoniam unaquaeque substantia hoc ipsum quod est non dicitur magis et minus; ut est haec substantia homo, non est magis et minus homo, neque ipse neque alter ab altero"; s. Anselmo, De grammatico c. 10 (ed. Schmitt, Opera 1) 154-155: "[Magistro] Memento dictorum Aristotelis quae paulo ante dixi, quibus dicit grammaticum et primam et secundam substantiam, quia et quendam hominem, et hominem et animal grammaticum dici testatur. Sed tamen unde probas grammaticum non esse primam nec secundam substantiam? - [Discipulus] Quia est in subiecto, quod nulla substantia est; et dicitur de pluribus, quod primae non est; nec est genus aut species nec dicitur in eo quod quid, quod est secundae".

31 S. Anselmo, Monol. c. 4 (ed. Schmitt, Opera 1) 17: "Cum igitur naturarum aliae aliis negari non possint meliores, nihilominus persuadet ratio aliquam in eis sic supereminere, ut non habeat se superiorem. Si enim huiusmodi graduum distinctio sic est infinita, ut nullus ibi sit gradus superior quo superior alius non inveniatur, ad hoc ratio deducitur, ut ipsarum multitudo naturarum nullo fine claudatur. Hoc autem nemo non putat absurdum, nisi qui nimis est absurdus. Est igitur ex necessitate aliqua natura, quae sic est alicui vel aliquibus superior, ut nulla sit cui ordinetur inferior". 
bible que el ser supremo se encuentre sometido a otro, ya que es absolutamente uno y simple. Al respecto, nuestro autor demuestra la contradicción que se concluye de la afirmación de una pluralidad de seres supremos. En efecto, dado que la supremacía no puede consistir en algo diverso de los muchos seres supremos, sino común a ellos, eso común o es algo propio de su esencia, o bien es diverso de ella ${ }^{32}$. Sin embargo, en ambos casos se concluye la unidad del ser supremo. En el primero, si la supremacía es algo esencial para esas muchas naturalezas, su esencia sería una y, por consiguiente, se trataría en cada caso de una naturaleza, ya que esencia y naturaleza son lo mismo para nuestro autor ${ }^{33}$. En el segundo caso, dado que los seres supremos serían tales en virtud de la supremacía común a ellos, serían dependientes de ella en ese respecto, es decir, menores que ella y, por ende, habría algo mayor que los seres supremos, a saber, la supremacía misma, lo cual contradice dicho carácter absolutamente supremo ${ }^{34}$. Por lo tanto, en virtud de esta contradicción, y sobre la base de la primacía absoluta del ser supremo, el arzobispo de Canterbury puede sostener la existencia de este último con las siguientes palabras:

Por lo que si, ni por aquello que son, ni por otro, es posible que haya muchas naturalezas, con respecto a las cuales no haya nada más excelente que ellas [quibus nihil sit praestantius], de ninguna manera puede haber muchas naturalezas tales. Por lo tanto, solo queda afirmar que hay una única y sola naturaleza [unam et solam aliquam naturam] que es de tal modo superior a las otras, que no sería inferior a ningún otro. Pero lo que es de tal modo, es lo más grande y lo mejor de todo cuanto es. Hay, por lo tanto, una cierta naturaleza, que constituye el grado supremo de todo cuanto $\mathrm{es}^{35}$.

Si al inicio de este camino los distintos grados del bien ponían en evidencia su remisión intrínseca a la magnitud $\mathrm{y}$, al mismo tiempo, el carácter trascendental del bien, ahora que san Anselmo ha llegado al término de esta sección es posible apreciar claramente que la confluencia entre el ser supremo y sus determinaciones se consuma en su absoluta identidad. Esto quiere decir que la naturaleza divina no es una en un sentido meramente cuantitativo, sino más bien en sentido esencial, porque el ser supremo no se consuma en virtud de algo diverso de su esencia, pues entonces esta última sería dependiente de aquello. Asimismo, sus determinaciones tampoco pueden depender de la esencia divina, pues entonces no tendrían lugar en grado sumo, ya que serían inferiores a dicha esencia y, por ende, no serían propias

32 S. Anselmo, Monol. c. 4 (ed. Schmitt, Opera 1) 17: "Haec vero natura quae talis est, aut sola est aut plures eiusmodi et aequales sunt. Verum si plures sunt et aequales: cum aequales esse non possint per diversa quaedam, sed per idem aliquid, illud unum per quod aequaliter tam magnae sunt, aut est idipsum quod ipsas sunt, id est ipsa earum essentia, aut aliud quam quod ipsae sunt".

33 S. Anselmo, Monol. c. 4 (ed. Schmitt, Opera 1) 17: "Sed si nihil est aliud quam ipsa earum essentia: sicut earum essentiae non sunt plures sed una, ita et naturae non sunt plures sed una. Idem namque naturam hic intelligo quod essentiam".

34 S. Anselmo, Monol. c. 4 (ed. Schmitt, Opera 1) 17: "Si vero id, per quod plures ipsae naturas tam magnae sunt, aliud est quam quod ipsae sunt, pro certo minores sunt quam id, per quod magnae sunt. Quidquid enim per aliud est magnum, minus est quam id, per quod est magnum. Quare non sic sunt magnae, ut illis nihil sit maius aliud".

35 S. Anselmo, Monol. c. 4 (ed. Schmitt, Opera 1) 17: "Quod si nec per hoc quod sunt, nec per aliud possibile est tales esse plures naturas quibus nihil sit praestantius, nullo modo possunt esse naturae plures huiusmodi. Restat igitur unam et solam aliquam naturam esse, quae sic est aliis superior, ut nullo sit inferior. Sed quod tale est, maximum et optimum est omnium quae sunt. Est igitur quaedam natura, quae est summum omnium quae sunt". 
de ella. De esta manera, el grado supremo de confluencia, esto es, la absoluta identidad entre la esencia y sus determinaciones, se muestra como fundamento suficiente para la existencia del ser divino y, como consecuencia de ello, de todos los demás seres que provienen y dependen de él. Por lo tanto, es necesario afirmar que lo más real que puede ser concebido y tener lugar ha de consistir en algo uno, y que dicha unidad no hace sino constatar su absoluta perfección, dado que reafirma su completa suficiencia e independencia de cualquier otro ${ }^{36}$. Así, al final del capítulo, el monje de Aosta afirma la existencia de la esencia divina como un corolario a todo cuanto ha expuesto:

Por lo que hay una cierta naturaleza, o bien sustancia, o bien esencia, que por sí misma es buena y grande, y que por sí misma es esto que es, y por la cual es todo cuanto es verdaderamente bueno, grande o algo, y la que es el bien supremo, la magnitud suprema y el ser supremo -es decir, subsistente-, esto es, aquel grado supremo de todo lo que es ${ }^{37}$.

De esta manera, el arzobispo de Canterbury confirma que las diversas propiedades que se entendían en principio a partir de una confluencia en la esencia divina, en realidad se identifican mutuamente en virtud de su pertenencia a esta última. Dicha identidad se basa, por su parte, en el carácter absolutamente suficiente de la esencia divina, la cual no solo es fundamento suficiente de su propia existencia, sino que también da lugar a que todo lo demás que pertenece al ámbito del ser al menos sea posible. Sin embargo, esta descripción de la manera en que se constituye la esencia divina, en la medida en que parte desde aquello que es conocido en cuanto tiene lugar en las criaturas, plantea otra interrogante, relativa a cuál sería el fundamento para que eso que se reconoce como propio de las criaturas trascienda ese ámbito y sea concebido a la vez como propio de la esencia divina. Esa pregunta es crucial para la meditación llevada a cabo por san Anselmo, ya que hasta que no se constate que es posible atribuir una determinación propia de las criaturas a Dios ni se delimiten los términos según los cuales es lícita dicha atribución, en la medida en que la trascendencia de un ámbito al otro no sería contradictoria, la meditación sobre la esencia divina poseerá un carácter meramente hipotético. Ahora bien, la pregunta por la trascendencia no se reduce a la posibilidad de que haya propiedades o perfecciones comunes tanto a Dios como a las criaturas, también se extiende al modo en que es concebida dicha trascendencia y cómo se concibe la esencia divina a partir de las perfecciones comunes. Como respuesta a esa pregunta, el monje de Aosta propone una determinación de los parámetros dentro de los cuales se concibe esas nociones comunes, y esa determinación se resume en una breve sentencia, que luego será conocida por los doctores de la Escolástica como la "regula Anselmi".

36 S. Anselmo, Monol. c. 4 (ed. Schmitt, Opera 1) 17: "Hoc autem esse non potest, nisi ipsa sit per se id quod est, et cuncta quae sunt, sint per ipsam id quod sunt. Nam cum paulo ante ratio docuerit id quod per se est et per quod alia cuncta sunt, esse summum omnium existentium: aut e converso id quod est summum, est per se et cuncta alia per illud, aut erunt plura summa. Sed plura summa non esse manifestum est".

37 S. Anselmo, Monol. c. 4 (ed. Schmitt, Opera 1) 17-18: "Quare est quaedam natura vel substantia vel essentia, quae per se est bona et magna, et per se est hoc quod est, et per quam est, quidquid vere aut bonum aut magnum aut aliquid est, et quae est summum bonum, summum magnum, summum ens sive subsistens, id est summum omnium quae sunt”. 


\subsection{La "regula Anselmi" y los términos según los cuales la razón es capaz de concebir la esencia divina a partir de las perfecciones comunes a ambos}

Uno de los puntos centrales del Monologion se encuentra en el capítulo 15, donde Anselmo expone los términos en que es posible afirmar algo de la esencia divina. Allí nuestro autor presenta un análisis del modo en que se debe concebir la perfección suprema, para que en ese mismo sentido se conciba todo cuanto se puede considerar como propio del ser supremo. Ese análisis y la regla que resulta de él, sin duda, constituyen un hito para la escolástica, como se aprecia en la importancia que figuras de la envergadura de Enrique de Gante y Juan Duns Escoto le asignan a la regla que llaman con el nombre de "regula Anselmi"38.

Al comienzo del capítulo, el arzobispo de Canterbury sostiene que, a pesar de que sería muy asombroso que términos mediante los cuales se pone de manifiesto aquello que surgió de la nada $-\mathrm{y}$ que, por ende, cualquier perfección que posea no proviene ni depende de él, sino más bien de aquel que lo creó- fueran capaces de expresar algo que convenga a la sustancia de su creador, de cualquier manera corresponde al menos intentar ver qué tan lejos puede llegar ese modo de concebir la sustancia divina, un modo que proviene de la misma razón humana ${ }^{39}$. Lejos de constituir una simple declaración retórica, mediante la cual exultaría al creador y a la vez reafirmaría la posición que niega que el intelecto sea capaz de alcanzar un conocimiento perfecto de la esencia divina en esta vida, esta observación plantea los términos y el alcance de la investigación puramente racional de las propiedades del ser supremo. En este sentido, la indagación parte de una exclusión de todo aquello que, en cuanto ese "algo" que es, no puede ser un predicado adecuado para la esencia divina, para que así queden en evidencia las propiedades y el modo según el cual sí es lícito atribuir a Dios.

De esta manera, san Anselmo descarta de plano una predicación relativa, pues, dado que la categoría de la relación no pone de manifiesto nada que pertenezca a la sustancia, no sería adecuada para afirmar algo que sea propio de la sustancia divina ${ }^{40}$. De esta exclusión se podría llegar a concluir una paradoja en lo que respecta a su modo de proceder hasta ahora-sobre la base de una jerarquización de bienes, en cuya cima se encuentra el bien supremo-, pues es imposible que el carácter supremo del ser

38 Cf. Enrique de Gante, Summa (Quaestiones ordinariae) a. 32 q. 1 sol. (ed. R. Macken, Ancient and Medieval Philosophy, Series 2, vol. 27, Leuven University Press, Leuven 1991) 31: "Et secundum regulam praedictam Anselmi..."; ibid. q. 2 sol. (ed. Macken, AMPh s. 2, 27) 46: "Dictam regulam de attribuendis Deo per proprietatem et non attribuendis consideravit Anselmus, quando dixit, Monologio, 15 cap...”; ibíd. 48: "Regulam ergo suam sic intellectam, ut iam dictum est, Anselmus applicat ad propositum dicens..."; JuAn Duns Escoto, Ordinatio I d. 8 n. 195 (ed. Commissionis Scotisticae, Opera omnia, vol. 4, Typis Polyglottis Vaticanis, Civitas Vaticana 1956) 262: "Regula Anselmi, Monologion 15: 'Necesse est ut sit quidquid omnino melius est ipsum quam non ipsum'"; H. SCHRÖCKER, Das Verhältnis der Allmacht Gottes zum Kontradiktionsprinzip nach Wilhelm von Ockham (Akademie Verlag, Berlin 2003) 227-230; 307-310; Aertsen, Medieval Philosophy, 390-393.

39 S. Anselmo, Monol. c. 15 (ed. Schmitt, Opera 1) 28: "lam non immerito valde moveor quam studiose possum inquirere, quid omnium quae de aliquo dici possunt, huic tam admirabili naturae queat convenire substantialiter. Quamquam enim mirer, si possit in nominibus vel verbis quas aptamus rebus factis de nihilo reperiri, quod digne dicatur de creatrice universorum substantia: tentandum tamen est, ad quid hanc indagationem ratio perducet”. Aunque la traducción de J. Alameda todavía sirve como punto de referencia en castellano, en este capítulo en particular su versión debe ser leída siguiendo atentamente el texto latino, ya que entiende el argumento en términos existenciales, cf. más abajo, nota 45.

40 S. Anselmo, Monol. c. 15 (ed. Schmitt, Opera 1) 28: "Itaque de relativis quidem nulli dubium, quia nullum eorum substantiale est illi de quo relative dicitur. Quare si quid de summa natura dicitur relative, non est eius significativum substantiae". 
divino dependa de su relación con los demás seres, que son inferiores a él, en la medida en que la existencia de estos últimos no añade ninguna perfección al creador. Sin embargo, el resultado principal de dicho examen, el carácter esencial de la supremacía de la naturaleza divina, implica que, incluso si no existiera ninguna otra naturaleza además de ella -y, por lo tanto, no se pudiera concebir como la sustancia más grande de todas o como el grado supremo de ser-, no por ello sería menos buena, su magnitud no se vería disminuida, ni su esencia sería en ninguna medida menos perfecta. Por lo tanto, la determinación del carácter supremo de la esencia divina presentaría en términos positivos lo que había sido expresado hasta ahora de manera negativa.

De este modo, el carácter supremo de la naturaleza divina, que el monje de Aosta exponía mediante una negación, como aquello que no es concebible que se encuentre bajo ningún otro ni que dependa de otro, debe ser entendido en el sentido de que la esencia divina es fundamento suficiente para sí misma en lo que respecta al despliegue de todas sus operaciones esenciales, de todo su ser ${ }^{41}$. Dicho de otro modo, puesto que Dios es un ser esencialmente supremo, y ese carácter no depende de la existencia de otra naturaleza -sea superior o inferior-, se puede concebir sin contradicción esa supremacía prescindiendo de un grado inferior de perfección, pues su perfección es tal, que supera cualquier gradación ${ }^{42}$. Por lo tanto, toda determinación que se conciba según los términos de dicha supremacía, que se observa en un principio en las criaturas y luego se atribuye a Dios, permite que nos acerquemos a la esencia del ser supremo, aun cuando no sea capaz de poner de manifiesto la esencia divina en su absoluta perfección ${ }^{43}$.

Por consiguiente, si de acuerdo con el arzobispo de Canterbury es posible que algunas determinaciones que tienen lugar en las criaturas permitan concebir aquello que es propio de la esencia divina, se vuelve entonces necesario establecer los parámetros a partir de los cuales sería posible identificar en términos generales cuáles son las determinaciones que pueden ser atribuidas como propias de la esencia divina, es decir, las condiciones para que una determinación pueda ser concebida como propia tanto de Dios como de las criaturas. San Anselmo presenta dichos parámetros en los siguientes términos, que luego fueron conocidos con el nombre de "regula Anselmi". La formulación de esta regla, en extremo precisa, hace difícil una traducción literal. Por ello, a continuación, se reproducirá el texto latino, para que a partir de la explicación posterior se proponga una traducción, al menos aproximada, en castellano:

Quidquid est praeter relativa, aut tale est, ut ipsum omnino melius sit quam non ipsum, aut tale ut non ipsum in aliquo melius sit quam ipsum. "Ipsum” autem et

41 S. Anselmo, Monol. c. 15 (ed. Schmitt, Opera 1) 28: "Si enim nulla earum rerum umquam esset, quarum relatione summa et maior dicitur, ipsa nec summa nec maior intelligeretur: nec tamen idcirco minus bona esset aut essentialis suae magnitudinis in aliquo detrimentum pateretur. Quod ex eo manifeste cognoscitur, quoniam ipsa quidquid boni vel magni est, non est per aliud quam per seipsam".

42 Cf. Aristóteles, Cat. c. 5, 3b 34-37 (ed. Minio-Paluello, AL I²) 52: "Videtur autem substantia non suscipere magis et minus; dico autem hoc non quia substantia non est a substantia magis et minus (hoc autem dictum est quia est); sed quoniam unaquaeque substantia hoc ipsum quod est non dicitur magis et minus"; s. ANSELMo, De gramm. c. 2 (ed. Schmitt, Opera 1) 146: "Omnis grammaticus suscipit magis et minus, et nullus homo suscipit magis et minus".

43 S. AnSElmo, Monol. c. 15 (ed. Schmitt, Opera 1) 28: "Si igitur summa natura sic potest intelligi non summa, ut tamen nequaquam sit maior aut minor quam cum intelligitur summa omnium: manifestum est quia 'summum' non simpliciter significat illam essentiam quae omnimodo maior et melior est, quam quidquid non est quod ipsa. Quod autem ratio docet de 'summo', non dissimiliter invenitur in similiter relativis”. 
"non ipsum" non aliud hic intelligo quam verum, non verum; corpus, non corpus; et his similia ${ }^{44}$.

Dado que toda predicación relativa viene inmediatamente excluida, resulta que la regla está planteada en términos absolutos, esto es, tomando en consideración aquello que constituye intrínsecamente toda determinación, su quiditas. En esos términos, es posible observar en ella un aspecto afirmativo y otro negativo. El primero sostiene que aquello que se afirma de la esencia divina debe constituir un "algo" que -considerado solamente a partir de su determinación en cuanto ese "algo"-, es de suyo mejor que su contrario. El segundo, que la presencia en otro de lo que está inmediatamente excluido de la determinación propia de "algo" -la afirmación del "no-algo"- debe ser mejor para eso otro en lo que tiene lugar, que la presencia de aquel "algo". Así, el punto en torno al cual se estructura la regla, radicaría en el "algo" (ipsum) o el "no-algo" (non ipsum), que simplemente, a partir de su determinación propia, es mejor que su contrario, ya sea en términos absolutos o en vista de su presencia en otro, y no en el hecho de que algo sea o no, es decir, que exista o $\mathrm{no}^{45}$.

Lo que san Anselmo llama "algo" y "no-algo" se puede entender del siguiente modo. "Algo" consistiría en aquello de lo cual es posible formar un concepto determinado, al tiempo que su contrario, el "no-algo", en la medida en que niega un "algo" determinado, consistiría en todo lo que se encuentra de suyo excluido de lo que es propio del primer "algo". Dicha negación, por su parte, no anularía de ninguna manera el "no-algo", ya que tanto éste como "algo" son posibles en sí mismos, en la medida en que pueden ser concebidos como al menos capaces de ser, condición mínima para pertenecer al ámbito del ser. De hecho, este es el primer sentido en que Boecio define "naturaleza", a saber, como eso que es propio "de aquellas cosas que, en la medida en que son, de algún modo pueden ser comprendidas por el intelecto" 46 . Tal definición expresa el sentido más amplio en que se puede concebir la noción de ser, dado que conviene a todo cuanto pertenece a dicha esfera. En efecto, como explica el filósofo romano, incluye a la sustancia y a los accidentes, a Dios y a la materia - los cuales, si bien no pueden ser comprendidos por completo por el intelecto humano, en atención a su grado supremo o ínfimo de perfección, sí pertenecen al ámbito del ser-. Lo único que quedaría fuera sería el absoluto no-ser, el cual, si bien posee un sentido, no posee naturaleza, ya que "toda naturaleza es", es decir, pertenece al

44 S. Anselmo, Monol. c. 15 (ed. Schmitt, Opera 1) 28.

45 La traducción del Alameda (Obras completas, 229), en cambio, gira en torno a la existencia: “... todo lo que no es del número de las cosas relativas es tal, que es mejor siendo que no siendo, o tal, que la no existencia es para él en ciertos casos mejor que el ser”. Compárese la presente exposición con el análisis de B. LEFTOw, “Anselm’s Perfect-Being Theology", en B. Davies - B. Leftow (eds.), The Cambridge Companion to Anselm to Anselm (Cambridge University Press, Cambridge 2004) 132-156, en particular 135-139; SchröcKER, Das Verhältnis, 224-226.

46 Boecio, Contra Eutychen et Nestorium c. 1 (ed. C. Moreschini, Saur, Monachii - Lipsiae 2005) 209: "Natura est earum rerum quae, cum sint, quoquo modo intellectu capi possunt". Esta definición recoge lo que sostiene Platón en el Sofista, cuando distingue aquello que pertenece al ámbito del ser de la nada absoluta; cf. PLATÓN, Soph. 236 d-239 c; H. Guerrero-Troncoso, "Las dos caras del no-ser. Una aproximación a la noción de ser

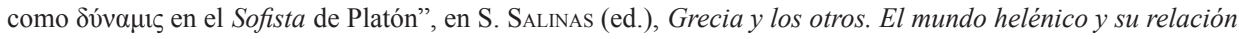
con otros pueblos a través de su historia: visiones, reflexiones, encuentros y perspectivas. Actas del VI Congreso Internacional de Estudios Griegos (Centro de Estudios Clásicos, Santiago de Chile 2020, en curso de publicación). 
ámbito del ser, y esto excluye inmediatamente al absoluto no-ser, lo "ninguno", dado que de éste no se puede afirmar ni siquiera que sea "algo" o "uno"47.

\subsection{La doctrina aviceniana de las primeras nociones del intelecto como punto de comparación para interpretar la regla anselmiana}

Ahora bien, si la regla anselmiana se debe entender a partir de la oposición entre "algo" y "no-algo" y no desde la existencia o la presencia en otro, es decir, si gira en torno al "ipsum" en lugar del "esse", resulta que nuestro autor tendría una comprensión del modo en que se articula la realidad diversa del sentido tradicional, esto es, de la comprensión propia de la "primera metafísica", que aspira sobre todo a describir lo que es propio del ser supremo y su articulación con los demás seres ${ }^{48}$. Esta posición alternativa se estructuraría sobre la base de una distinción clara entre lo que determina en cada caso a todo "algo", su quiditas, y las condiciones a partir de las cuales es posible que "algo" se constituya como ese "algo" que es y despliegue su propio ser, y que al mismo tiempo permiten que se dé a conocer en cuanto tal. En este punto, los téminos en que Avicena plantea la distinción y la confluencia de las nociones de res y ens-que influyeron profundamente la interpretación de la regla anselmiana por parte de autores como Enrique de Gante y Juan Duns Escoto- permiten comprender de mejor manera las implicancias de la oposición entre "algo" y "no-algo", aun cuando san Anselmo no haya tenido ninguna posibilidad de conocer las obras del filósofo persa ${ }^{49}$.

Si bien una exposición detallada de la doctrina aviceniana como clave de lectura de la regla anselmiana supera los límites de este trabajo, se pueden delinear brevemente tres aspectos de ella que son relevantes para la interpretación propuesta ${ }^{50}$. El primero consiste en el carácter primario que poseen para el filósofo persa las nociones de res, ens y necesse, en lo que respecta a la constitución de la realidad y al reconocimiento de ella en cuanto real. En este sentido, las condiciones a partir de las cuales se concibe la realidad pasan a ser al menos tan importantes como su descripción, ya que toda comprensión de esa realidad se estructura a partir de las nociones que están inmediatamente presentes en el intelecto ${ }^{51}$. En segundo lugar, a partir del

47 Boecio, Contra Eutychen c. 1 (ed. Moreschini) 209-210: "In hac igitur definitione et accidentia et substantiae definiuntur; haec enim omnia intellectu capi possunt. Additum vero est 'quoquo modo', quoniam Deus et materia integro perfectoque intellectu intelligi non possunt, sed aliquo tamen modo ceterarum rerum privatione capiuntur. Idcirco vero adiunximus 'quae cum sint', quoniam etiam ipsum nihil significat aliquid, sed non naturam. Neque enim quod sit aliquid, sed potius non esse significat; omnis vero natura est. Et si de omnibus quidem rebus naturam dici placet, haec sit naturae definitio quam superius proposuimus".

48 Cf. Honnefelder, "Metaphysik des Ersten", 443-445.

49 Cf. Avicena, Metaph. I c. 5 (ed. van Riet, AviL 3) 31-32: "Dicemus igitur quod res et ens et necesse talia sunt ut statim imprimuntur in anima prima impressione, quae non acquiritur ex aliis notioribus se, sicut credulitas quae habet prima principia, ex quibus ipsa provenit per se, et est alia ab eis, sed propter ea"; T.-A. DRUART, " «Shay"» or «Res» as Concomitant of «Being» in Avicenna", en Documenti e studi sulla tradizione filosofica medievale 12 (2001) 125-142; M. PICKAVÉ, Heinrich von Gent über Metaphysik als erste Wissenschaft. Studien zu einem Metaphysikentwurf aus dem letzten Viertel des 13. Jahrhunderts (Brill, Leiden - Boston 2007) 195201; Koutzarova, Das Transzendentale bei Ibn Sīnā, 339-362; A. Bertolacci, "The Distinction of Essence and Existence in Avicenna's Metaphysics: The Text and its Context", en F. Opwis - D. ReISman (eds.), Islamic Philosophy, Science, Culture, and Religion. Studies in Honor of Dimitri Gutas (Brill, Leiden - Boston 2012) 257-288.

50 Para un análisis más detallado, cf. H. Guerrero-Troncoso, "San Anselmo y los albores de la scientia transcendens. Una interpretación aviceniana de la 'regula Anselmi"”, en Anuario Filosófico [en curso de publicación].

51 Avicena, Metaph. I c. 5 (ed. van Riet, AviL 3) 31-36, en particular 32: "Nisi enim prius subintraverit animum vel nisi fuerit intellectum quod significatur per verbum, non poterit cognosci id quod significatur per illam". 
análisis de las relaciones entre res y ens se pueden definir con mayor claridad sus respectivas determinaciones propias. Por una parte, Avicena sostiene que ens es una noción concomitante con res, en la medida en que ens se concibe en cada caso como aliquid, como "un ser" que en cada caso es "algo". Este último, por su parte, se remite a aquello en virtud de lo cual es ese "algo" que es y no otro, su determinación propia (certitudo), su quiditas, su ser propio. Ese sería el sentido de res, en el cual confluiría este sentido de ens. Por otra parte, el filósofo persa observa que hay seres que tienen lugar en el intelecto y fuera de él, y otros que solo se encuentran en el intelecto, pero en ambos casos la noción de ser designa eso que en cada caso se hace presente. Tal designación implicaría siempre un advenimiento, ya que todo aquello que no es propio de la quiditas de una cosa, pero igualmente tiene lugar en ella porque permite su despliegue, adviene en ella, aun cuando no constituya esencialmente esa cosa. Así, en la medida en que permite el despliegue de todo "algo" mediante el advenimiento de aquello que lo designa y que a la vez le es extrínseco, Avicena afirma expresamente la identidad entre advenir y este sentido de ser, diverso de res y más amplio ${ }^{52}$. Por último, en tercer lugar, nuestro filósofo plantea la distinción entre Dios y las criaturas como una oposición entre un ser necesario, cuya verdad no depende de otro, y los otros seres, que en sí son falsos y cuya verdad proviene del ser necesario. De acuerdo con esa distinción, el ser necesario es concebido como incausado, mientras que la causalidad sería propia de las criaturas ${ }^{53}$.

Sobre la base de estos elementos, sería posible interpretar la regla anselmiana como una fórmula que establece los parámetros según los cuales una cierta determinación del ámbito de las criaturas sería capaz de trascender dicho ámbito, para poner de manifiesto algo que se debe entonces considerar como propio de la esencia divina. En efecto, es posible sostener que la regla anselmiana se articula a partir de lo que Avicena concibe como res, es decir, a partir de la determinación propia de cada "algo", de su certitudo, su quiditas. Dicha determinación propia sería en cada caso irreductible, pues consiste en aquello primero a partir de lo cual cada "algo" se constituye en cuanto "este 'algo" y ya no se puede resolver en nada más simple que eso: el hombre se constituye en cuanto tal a partir de la humanidad, el caballo, a partir de la caballidad, a pesar de que compartan las determinaciones de "sustancia", "animal", "mamífero", etc. Solo a partir de la propia certitudo es posible que se articulen y advengan en ellos las determinaciones sucesivas que los designan, mediante las cuales se inserta cada "algo" en el entramado de la realidad y se despliegua de acuerdo con el lugar que le corresponde.

Por consiguiente, la primera parte de la regla anselmiana postularía que es posible concebir el ser supremo a partir de todo aquello cuya determinación propia -que lo constituye en cuanto "ese "algo" (ipsum) - posee una perfección intrínseca tal, que lo califica inmediatamente como mejor que su contrario, es decir, mejor que el "algo" que se constituye como tal a partir de una negación de todo lo que es propio de ese

52 Avicena, Metaph. I c. 5 (ed. van Riet, AviL 3) 36-39, en particular 37: "Sensus enim nostrae dictionis, quod non esse est tale [scilicet, quod aliquo modo designari potest], est quod talis dispositio advenit in non esse; nec est differentia inter advenire et esse; et ideo idem est quasi diceremus quod haec proprietas habet esse in non esse".

53 Avicena, Metaph. I c. 6 (ed. van Riet, AviL 3) 43: "Dicemus igitur quod necesse esse per se non habet causam et quod possibile esse per se habet causam"; ibíd. c. 8 (ed. van Riet, AviL 3) 55-56: "Necesse esse est id quod per seipsum est veritas semper; possibile vero est veritas per aliud a se, et est falsum in seipso. Quicquod igitur est praeter necesse esse quod est unum, falsum est in se ... Ex dictionibus autem veris, illa est dignior dici vera cuius certitudo est semper; sed quae dignior est ad hoc est illa cuius certitudo est prima, et non per causam". 
"algo" (non ipsum). Así, se debe concebir a Dios, sobre todo, a partir de aquello que es perfecto en sí mismo, en virtud de su mera certitudo y que, por ello, implica una perfección para todo aquello en donde tiene lugar. San Anselmo ilustra este primer criterio mediante el ejemplo de que en cada caso es mejor que algo sea sabio, justo, verdadero o viviente, es decir, que en ese "algo" tengan lugar la sabiduría, la justicia, la verdad o la vida, a que tengan lugar en ello las determinaciones contrarias, la nosabiduría, la no-justicia, etc. Por el contrario, todo "algo" que excluye de sí una determinación intrínsecamente perfecta, se debe considerar inferior a lo que se incluye en dicha perfección, dado que ella consiste de suyo en algo en virtud de lo cual la sustancia en la que se hace presente puede ser concebida como más digna y mejor ${ }^{54}$. La primera parte de la regla expresaría, por lo tanto, el fundamento de la validez de la atribución de una propiedad a la esencia divina, el cual consistiría en que toda propiedad que posee un carácter intrínsecamente perfecto, que la hace inmediatamente mejor que su contrario, puede ser considerada como propia de Dios.

La segunda sección de la regla, por su parte, mostraría la otra cara de la primera, ya que el mismo principio - la perfección intrínseca de un "algo" determinado-, permite negar la atribución de un "algo" dado a la esencia divina, en la medida en que la presencia de ese "algo" en Dios implique un detrimento para su perfección absoluta. Por lo tanto, en lugar de predicar un cierto "algo" de la esencia divina, se debería predicar más bien su contrario, el "no-algo". En este sentido, san Anselmo no niega que la propiedad posea una cierta perfección -puesto que todo "algo", por el hecho de ser tal, contiene en sí un cierto grado de perfección-, menos aun su pertenencia al ámbito del ser -ya que el "no-algo", en cuanto "no-nada", es igualmente "algo" y, por ende, pertenece a esa esfera-, más bien pone en evidencia que hay propiedades incompatibles con el carácter suficiente e intrínseco de la perfección de la esencia divina, pues la perfección de esas propiedades no es absoluta, sino que está condicionada por aquello en donde tiene lugar. En efecto, si una esencia es más digna o mejor debido a la presencia de algo que adviene en ella, que le es extrínseco, se concluye que dicha esencia depende de ese "algo" y, así, dado que no es perfecta en sí misma, es mejor que sea concebida a partir de ese "algo". Por el contrario, en el caso de la esencia divina, puesto que no se encuentra sometida a otro ni depende de él, es mejor que sea concebida con exclusión de la propiedad que se le pretende atribuir, ya que conlleva un detrimento para su perfección. El ejemplo que propone Anselmo ilustra claramente este punto: para el hombre es mejor que no sea de oro, ya que la naturaleza humana es mejor y más digna que la del oro, pues es un metal que no permite la vida, la cual constituye una perfección intrínseca del hombre, mayor que la nobleza o el valor que el oro pueda tener para el comercio. Para el plomo, por el contrario, cuya naturaleza es inferior a la del oro, sería mejor que fuera de ese metal, porque así su valor aumentaría ${ }^{55}$.

54 S. Anselmo, Monol. c. 15 (ed. Schmitt, Opera 1) 28-29: "Melius quidem est omnino aliquid quam non ipsum, ut sapiens quam non ipsum sapiens, id est: melius est sapiens quam non sapiens. Quamvis enim iustus non sapiens melior videatur quam non iustus sapiens, non tamen est melius simpliciter non sapiens quam sapiens. Omne quippe non sapiens simpliciter, inquantum non sapiens est, minus est quam sapiens; quia omne non sapiens melius esset, si esset sapiens. Similiter omnino melius est verum quam non ipsum, id est quam non verum; et iustum quam non iustum; et vivit quam non vivit".

55 S. Anselmo, Monol. c. 15 (ed. Schmitt, Opera 1) 29: "Melius autem est in aliquo non ipsum quam ipsum, ut non aurum quam aurum. Nam melius est homini esse non aurum quam aurum, quamvis forsitan alicui melius esset aurum esse quam non aurum, ut plumbo. Cum enim utrumque, scilicet homo et plumbum, sit non aurum: tanto melius aliquid est homo quam aurum, quanto inferioris esset naturae, si esset aurum; et plumbum tanto vilius est, quanto pretiosius esset, si aurum esset". 
En resumen, se puede decir que san Anselmo presupone que todo "algo" posee un grado mínimo de perfección, que le correspondería por el simple hecho de pertenecer al ámbito del ser, y, asimismo, un grado máximo de perfección que le sería lícito alcanzar, de acuerdo con su determinación propia. Así, a todo "algo" le correspondería uno de estos dos tipos de perfección, o bien aquella, cuyo grado de perfección intrínseca es tal, que su contrario conlleva inmediatamente una imperfección, o bien esa, cuya perfección o imperfección depende de aquello en lo que tiene lugar. En el primer caso, se trataría de determinaciones que pueden ser consideradas por sí mismas como propias tanto de Dios como de las criaturas, puesto que serían capaces de alcanzar el grado supremo de perfección; en el segundo caso, en cambio, dado que estarían condicionadas por la esencia en la cual tienen lugar, la negación de dichas determinaciones implicaría una perfección mayor, porque su negación se extendería asimismo a su carácter condicionado y, con ello, excluiría el grado de imperfección que importan para la esencia en la que tienen lugar.

De esta manera, el carácter suficiente o dependiente de esas determinaciones sería el fundamento para que sea lícito atribuir alguna de ellas a la esencia divina, o más bien su contrario. En consecuencia, todo cuanto es en sí mismo perfecto, en la medida en que conlleva una perfección por el solo hecho de hacerse presente, puede ser concebido como propio de la esencia divina y, por lo tanto, como trascendente, porque también tiene o puede tener lugar en las criaturas. Por el contrario, si la negación de "algo" implica también la exclusión de una condición intrínseca a este último, resulta que el "no-algo" es más perfecto que el "algo" y, por lo tanto, corresponde que sea concebido como propio de la esencia divina. La "regula Anselmi", entonces, se puede traducir de la siguiente manera:

Todo aquello que es, aparte de lo que es relativo, es de tal modo, que es totalmente mejor que él mismo tenga lugar, a que tenga lugar su contrario, o bien de tal modo, que es mejor que su contrario esté presente en algo, a que él mismo lo esté. Así, por "él mismo" [ipsum] y "su contrario" [non ipsum] no entiendo acá otra cosa sino "verdadero" - "no-verdadero", "cuerpo" - "no-cuerpo", y todo aquello que es similar a ellos.

\section{A modo de conclusión. Identidad, confluencia y trascendencia entendidas como presupuestos especulativos claves para interpretar el argumento del Proslogion y como antecedentes de una metafísica entendida como scientia transcendens}

Una vez terminado el análisis de los aspectos del Monologion relevantes para interpretar el argumento del Proslogion, corresponde comprobar la validez de la clave de interpretación en torno a la cual se articuló dicho examen, esto es, la pertinencia de los conceptos principales, identidad, confluencia y trascendencia. De acuerdo con la hipótesis inicial, ellos permitirían apreciar el camino que sigue Anselmo para describir las propiedades de la esencia divina y, a su vez, las condiciones a partir de las cuales sería lícito concebir dicha esencia en cuanto existente y en cuanto adecuada a esa descripción.

Así, las dos primeras nociones, identidad y confluencia, constituirían los términos a partir de los cuales se estructura una descripción de toda esencia y, en 
particular, de la esencia divina. Como se aprecia en la identificación entre bien, magnitud y esencia, entendidos en sentido supremo, este último aspecto, la esencia suprema, sería el fundamento de la identidad de todas las perfecciones divinas, las cuales a su vez serían en cada caso expresión de la perfección absoluta e intrínseca de aquella. La esencia divina, en cuanto tal, sería el bien supremo, éste, en cuanto tal, la magnitud suprema, esta última, en cuanto tal, la esencia divina, y así sucesivamente. Luego, si bien se puede afirmar, en palabras de Duns Escoto, que es posible concebir la esencia divina como aquello que contiene en sí todo lo que es simplemente una perfección (perfectio simpliciter) en el grado supremo ${ }^{56}$, no se debe suponer que dependa en alguna medida de sus perfecciones, que se reduzca o subyazga a ellas, como si fuera un sujeto en el cual advienen las perfecciones. Por el contrario, en esta absoluta identidad, es la esencia divina misma la que manifiesta su presencia en tanto bien supremo, magnitud suprema, o cualquier otra perfección en grado sumo.

Por su parte, si bien a toda esencia creada subyace igualmente una cierta identidad, el carácter dependiente de las criaturas redunda en que sus perfecciones no se identifiquen entre sí completamente, sino solo en la medida en que confluyen en una misma esencia. De este modo, a pesar de que constituyen una cosa sola con aquella sustancia en la cual tienen lugar, las diversas determinaciones mantienen su propia identidad, más o menos distinta de la esencia en la que están presentes. Por consiguiente, las criaturas se ponen de manifiesto siempre en y a partir de otro "algo", aun cuando este último no sea otra cosa, diversa de lo que se da a conocer. Así, por ejemplo, un caballo se pone de manifiesto en y a partir de su cuerpo, de su velocidad y de su fuerza, pero el caballo en cuanto tal constituye un "algo" diverso de estas determinaciones. Dado que recoge la distinción de las propiedades dentro de su identidad en la cosa, esa confluencia aparece como inherente a todo lo que es, de tal modo que el método que sigue Anselmo al inicio del Monologion no sería arbitrario, sino más bien adecuado a la manera en que se articula la realidad.

En este sentido, la noción de confluencia no se reduce a poner en evidencia cómo se estructura la relación entre la esencia y sus propiedades, sino que también abarca los límites y los modos en que la realidad puede ser concebida, y así decanta en la noción de trascendencia, la cual se puede entender principalmente en dos sentidos. En primer lugar, trascendental es algo que tiene lugar tanto en el ámbito de las criaturas como en el de la esencia divina. En segundo lugar, trascendental es el carácter que posee la relación entre conocimiento y realidad, en la medida en que esta última, por el simple hecho de pertenecer a la esfera del ser, de alguna manera se da a conocer. De acuerdo con el análisis llevado a cabo hasta ahora, en la regla de san Anselmo confluirían ambos sentidos del término. En efecto, en tanto que define los parámetros dentro de los cuales es lícito atribuir a la esencia divina una perfección que se encuentra en las criaturas, deja en evidencia qué puede ser concebido como trascendental y qué no y, de este modo, en la regla se encuentran tanto las condiciones que se estiman más adecuadas a la esencia divina como aquellas para que el intelecto humano sea capaz de concebir dicha esencia hasta donde le es posible.

56 J. Duns Escoto, Ord. I d. 3 n. 58 (Opera omnia 3, Typis Polyglottis Vaticanis, Civitas Vaticana 1954) 40: “Ad multos conceptus proprios Deo possumus pervenire, qui non conveniunt creaturis, - cuiusmodi sunt conceptus omnium perfectionum simpliciter, in summo. Et perfectissimus conceptus, in quo quasi in quadam descriptione perfectissime cognoscimus Deum, est concipiendo omnes perfectiones simpliciter et in summo". 
La breve alusión a la comprensión aviceniana de las primeras nociones del intelecto permitiría observar más claramente que la simple descripción de las determinaciones de la esencia divina y el reconocimiento de su perfección suprema no son suficientes para que el intelecto humano constate su existencia y la dependencia de las criaturas a Dios, sino que es necesario antes que nada reconocer explícitamente que esa descripción puede tener lugar solo a partir de los términos establecidos por aquellas primeras nociones, res, ens, necesse, etc. El hecho de que para Avicena esas nociones constituyan el punto de partida de la ciencia que se ocupa del ser en cuanto ser, significaría que las condiciones a partir de las cuales se estructura el conocimiento serían a su vez condición para que la realidad sea aprehendida en cuanto real y, por lo tanto, el rol del intelecto en dicha aprehensión no podría quedar oculto detrás de la descripción de la realidad, ya que los principios de esa descripción serían nociones que tienen lugar principalmente en el intelecto. La regla anselmiana, por su parte, dejaría también en evidencia ese aspecto gnoseológico, puesto que el reconocimiento de la existencia del ser supremo, en último término, depende en gran medida del modo en que el intelecto concibe los principios y la articulación de la realidad. De esta manera, la actividad del intelecto y el despliegue de la realidad, ser y pensar, estarían remitidos recíprocamente de modo intrínseco, trascenderían el uno en el otro por su propia operación, ya que el intelecto intelige solo aquello que pertenece al ámbito del ser y este último, a su vez, solo se hace efectivamente presente en la medida en que es pensado, es decir, en cuanto es reconocido como ese "algo" que es.

Esa remisión recíproca, esa confluencia en la que ser y pensar trascienden el uno en el otro sería, luego, el punto en torno al cual se articularía el argumento del Proslogion, y a ella apelaría san Anselmo inmediatamente antes de formular el argumento, cuando ruega a Dios que le haga comprender, cuanto considere conveniente, que su esencia es tal como cree que es, y que es aquello en lo que cree, a saber, algo, de lo cual nada mayor que él puede ser concebido: "Ergo, domine, qui das fidei intellectum, da mihi, ut quantum scis expedire intelligam, quia es sicut credimus, et hoc es quod credimus. Et quidem credimus te esse aliquid quo nihil maius cogitari possit ${ }^{\prime 57}$. Dicha identidad, fruto de la confluencia entre los diversos modos en que se manifiesta la esencia divina y en que el intelecto es capaz de concebirla, constituiría el fundamento de la verdad de la afirmación de la existencia de Dios, al menos en los términos en que la concibe nuestro autor, a saber, como "la rectitud que puede ser percibida por el intelecto solo" 58 . Por lo tanto, en virtud de la identidad entre el modo en que la esencia divina se ha dado a conocer -que es el modo en que el hombre cree que Dios es- y aquello que ésta es en cuanto tal -es decir, de la adecuación entre la cosa y el intelecto-, es posible reconocer que Dios verdaderamente es -o existe-, como reza el título del capítulo 2 del Proslogion ${ }^{59}$.

Como consecuencia de esta identidad entre ser y pensar, luego, es posible advertir que el argumento del Proslogion presupone una doble confluencia. La primera consistiría en que los términos a partir de los cuales el intelecto humano concibe la esencia divina deberían coincidir con los distintos aspectos según los cuales esta última se da a conocer al hombre. Dicha confluencia sería posible bajo el presupuesto de la validez de la regla del Monologion, que habría sido reformulada, en términos

\footnotetext{
S. Anselmo, Prosl. c. 2 (ed. Schmitt, Opera 1) 101.

S. Anselmo, De veritate c. 11 (ed. Schmitt, Opera 1) 191: "Veritas est rectitudo mente sola perceptibilis".

S. Anselmo, Prosl. c. 2 (ed. Schmitt, Opera 1) 101: "Quod vere sit Deus".
} 
más radicales aun, en el argumento del Proslogion. En efecto, si el intelecto humano concibe a Dios como aquello de lo cual nada mayor que él puede ser concebido, y todo cuanto es lícito concebir como propio de la esencia divina -en la medida en que sería algo intrínsecamente perfecto, o bien la negación de algo que no es en sí perfecto- viene entendido en sentido supremo, resultaría que el argumento pondría dicha supremacía como condición de validez para toda afirmación relativa a la esencia divina. En este sentido, el bien divino solo se puede concebir como el bien, con respecto al cual ningún bien mayor puede ser concebido, la magnitud divina, como aquella magnitud, con respecto a la cual ninguna magnitud mayor que ella puede ser concebida, y así sucesivamente. Por ende, en el argumento se concretaría la confluencia entre aquello que se cree como propio de Dios -"quia es sicut credimus"- y el modo en que Dios se da a conocer -"et hoc es quod credimus"-.

Por otra parte, esta primera confluencia presupondría la segunda, aquella que se da entre ser y pensar, que consistiría en una remisión recíproca. En otras palabras, la actividad del ser estaría remitida intrínsecamente al pensar, dado que solo aquello que es concebido como ese "algo" que es se hace efectivamente presente como tal, al tiempo que la actividad del pensar se remite intrínsecamente a la esfera del ser y a todo "algo" que tiene lugar en ella ${ }^{60}$. Precisamente de esa confluencia se ocuparía el resto del c. 2 del Proslogion, en el que Anselmo intenta demostrar que quien concibe a Dios según los términos del argumento y niega su existencia, incurre en contradicción y, por lo tanto, actúa como un insensato ${ }^{61}$. Dicha contradicción sería anterior a la descripción de las propiedades de la esencia divina, ya que diría relación con el aspecto central de la regla anselmiana y del argumento del Proslogion, a saber, el carácter supremo, suficiente e independiente de la esencia divina. Solo a partir de ese presupuesto tiene sentido cualquier descripción de dicha esencia desde sus propiedades. Sin embargo, dado que sobre este punto el intelecto no tiene más que sus propios principios para decidir la validez de lo que afirma de la esencia divina, ninguna descripción posterior es capaz de confirmar la existencia de Dios, ya que toda perfección divina -la bondad, la magnitud, etc.- presupone el carácter supremo. En este sentido, la comprensión aviceniana del carácter absolutamente primero de las nociones inmediatas serviría para ilustrar la función del argumento anselmiano, entendido como una fórmula que contiene los parámetros dentro de los cuales es posible concebir a la esencia divina del modo más adecuado a como ella se da a conocer, antes de cualquier descripción de sus propiedades. Dios no se podría comprender a partir de sus propiedades, como un conjunto de perfecciones que se reúnen de alguna manera en la esencia divina, sino más bien a partir de la absoluta identidad de aquella con la esencia suprema, la cual luego se refracta en sus diversas perfecciones. Esos serían los parámetros dentro de los cuales aquello en lo que se cree podría darse a conocer de una manera adecuada a la razón humana.

60 Cf. H. Guerrero-Troncoso, "Identidad o confluencia. Apuntes para una interpretación de la relación entre pensar y ser en Parménides”, en Byzantion Nea Hellás 38 (2019) 105-127, en particular 119-122.

61 Cf. S. Anselmo, Prosl. c. 3 (ed. Schmitt, Opera 1) 103: "Cur itaque 'dixit insipiens in corde suo: non est Deus', cum tam in promptu sit rationali menti te maxime omnium esse? Cur, nisi quia stultus et insipiens?". 